\title{
PERSONAL ADVERTISEMENTS AS TEXT COLONIES: FEATURES AND TYPES OF COLONIES
}

\section{Věra Šustáčková}

\begin{abstract}
The genre of personal advertisements is relatively new; nevertheless, various branches of the social and linguistic sciences deal with this text type since personal advertisements reflect social behaviour and attitudes and thus may provide information about language and society. The present paper studies personal advertisements from the perspective of text colonies and compares printed and online advertisements in order to explore the language manifestations of the communicative strategies employed by the two media. The study is carried out on advertisements published in The Times and placed on the dating website datingdirect.com.
\end{abstract}

\section{Keywords}

personal advertisements, colony text, mainstream text, components, The Times, Internet, simple and complex colonies

\section{Introduction}

In contemporary society, personal or 'lonely hearts' advertisements play an important role in seeking a potential partner. Many people use this way of meeting their ideal counterpart to solve the problem of loneliness, which has become a symptom of lifestyle of contemporary western society (Vlčková 1996). Technical innovations introduced over the past few years have attempted to make communication between people easier; on the other hand, since such communication does not involve face-to-face interaction, it may provoke a feeling of alienation. However, loneliness is not the only reason which prompts people to seek partners via advertisements. It is also the anonymity of the matrix of personal advertisements that makes them attractive to many people.

Personal advertisements first appeared in newspapers about 300 years ago and since then they have changed considerably with respect to their structure and character. In the beginning, this way of seeking partners was regarded as suspect or humiliating, or thought of as an admission of personal failure. People placing advertisements were automatically understood as bad, ugly, and unwanted. It was not until the twentieth century that personal ads gained in respectability and began to be accepted as an ordinary way of meeting new people (Cocks 2009). In the 1980s and 1990s this genre also caught the interest of sociologists, sociolinguists and linguists. Currently, personal advertisements are understood 
as a valuable source of information about society and culture, since they reflect social beliefs, values and habits.

The present paper attempts to contribute to the study of text colonies by comparing printed personal advertisements with their "modern cousins" (Cocks 2009), i.e. advertisements placed on the Internet. Although in the recent past, newspapers and magazines published the majority of personal ads (Vlčková 2000), nowadays, thanks to the expansion of Internet use, these advertisements appear predominantly on various dating websites. Thus, this paper focuses on personal advertisements from the perspective of text colonies and compares printed and online personal advertisements in order to explore the language manifestations of the communicative strategies employed by the two media. For this purpose, 100 personal advertisements (PAD) from The Times and the website datingdirect.com were chosen and analysed, 50 advertisements from each (PAD 1-50 from The Times, PAD 51-100 from datingdirect.com). Printed advertisements come from two issues published on September 10, 2011 and November 25, 2011. Advertisements taken from the website datingdirect.com come from the period from April 12, 2010 to March 7, 2011. The choice of ads was random. As for the media used for the present analysis, The Times is a traditional British daily newspaper based in London, having the British middle class as its target group. The website datingdirect.com is a British dating website where people may attempt to contact a potential partner. It is the UK branch of the Meetic Group, which was established in 2001 and is the largest online dating and chat service in the world, though known under different names across Europe. Unlike The Times, which targets educated people of middle age, this website does not have any particular range of users or visitors; it focuses on the general public and, thus, clients aged 18 and above and of all social classes and religions may use its services.

\section{The concept of text colonies}

The term discourse colony was first used by Hoey in his 1986 paper "The Discourse Colony” (Tomášková 2008). The subtitle of this paper - "A Preliminary Study of a Neglected Discourse Type" - was intended to draw the attention of linguists to a special text-type which was neglected and disregarded at that time, and thus to differentiate it from mainstream text, i.e. continuous types of text, such as novels or essays (ibid.). As Hoey (2001) emphasizes, people encounter discourse colonies every day and more frequently than mainstream texts; therefore, they deserve adequate attention. The terms 'discourse colony', 'text colony' (Tárnyiková 2002), or 'colony text' (Dontcheva-Navratilova 2006) thus define a specific type of text whose key feature is discontinuity. As Tomášková 
(2008) states, some colonies (e.g. TV guides, shopping lists, advertisements, class lists, telephone books, dictionaries, cookery books) are created from a set of components whose mutual connection is almost impossible, while others (CVs, FAQs or thesis review assessments) intentionally change their structure and become colonies.

Hoey labels colonies "Cinderella texts" since these kinds of text "received short shrift from discourse analysts as well, if indeed they have been noticed at all" (Hoey 1996: 150), which, according to Hoey, is not a consequence of their low significance but of "a restricted notion of reading as a linear processing of text" (ibid.). The role of the reader when dealing with a text colony is thus different. One can skim colonies, making general connections between sentences; read them carefully, perceiving connections between sentences with great care; or scan them, seeking only those pieces of information that are somehow relevant or important to oneself (Hoey 2001). The last mentioned strategy is typical of most text colonies, including personal advertisements. For instance, for better reader orientation, advertisements in The Times are divided into four sections, i.e. Women seeking men, Men seeking women, Men seeking men, and Women seeking women. Thus, when a reader goes through the ads, he/she does not need to read every one, but probably aims his/her attention at one section only. Another option is to scan ads for particular information or features, e.g. age of advertiser, first line of the advertisement, particular key words. As far as advertisements published on the Internet are concerned, seeking relevant information in such ads is much easier than in the case of The Times since suitable advertisements are displayed according to filter settings which specify the required features of a potential partner, e.g. age, location, hair colour, interests. Thus, one can browse only the ads meeting these requirements.

\section{Analysis of the text-colony features of personal advertisements}

To characterize and describe the basic features of text colonies, Hoey uses an analogy from the natural world, comparing the structural principles of colonies in terms of a metaphor involving beehives. He suggests a working definition of this text-type, stating that "a colony is a discourse whose component parts do not derive their meaning from the sequence in which they are placed" (Hoey 2001: 75) and adds that "if the parts are jumbled, the utility may be affected but the meaning remains the same" (ibid.). Besides the key feature of colony texts presented in this tentative definition, Hoey identifies eight further features (Hoey 2001: 75-87). In the following lines these features of text colonies will be applied to both printed and on-line advertisements and examples will be included:

1) The meaning of a discourse colony is not derived from the sequence of its components; 
Both advertisements in The Times and on the website datingdirect.com are placed in a sequence but do not derive their meaning from their position in the sequence, which is manifested in the following example extracted from The Times:

Example 1:

[PAD 2] Public school and university-educated lady, 68, interested in the arts, walking, good food and wine, seeks companion with similar background. Ldn. Call 09056756709 Voicebox 55803.

[PAD 3] Sophisticated, attractive, slim female, with many interests, WLTM a fun loving man, 60+, for sharing, caring and romantic escapades. Ldn/Bucks/Beds/Herts. Call 09056756709 Voicebox 07252.

The Times, September 10, 2011

2) Adjacent units do not form continuous prose;

Neither ads published in The Times nor those placed on datingdirect.com form continuous prose; i.e. they are not connected (cf. Example 1 above).

3) There needs to be a framing context providing conditions for the interpretation of the text;

A framing context is important in order to interpret personal advertisements as such. In The Times, a double page is devoted to personal advertisements. The ads are not placed randomly but, as has already been mentioned, are organized into four sections and, thus, the reader going through the advertisements needs only to focus on the section that he/she is interested in. Advertisements published in The Times contain bare text, without titles, subtitles, or photographs. As for datingdirect.com, the framing context is the website itself. Obviously, the names of the websites usually indicate their orientation towards personal advertisements, e.g. date.com, match.com, speeddate.com etc. A website in general may be seen as a hypertext, whose specific basis is its organization, in which texts are interconnected by various links so as to allow the user to focus his/her attention on the target information without needing to go through all the available hypertext (Tomášková 2008). This is exactly how advertisements published on datingdirect.com work. Each ad takes up one page and if the reader wishes to read another advertisement, he/she has to follow various references (hyperlinks), e.g. New people, Members online, Search, Connections etc. After clicking on one of the hyperlinks or setting the requirements for potential partners, previews of suitable advertisements containing the age and/or location of the advertiser along with the introductory sentence of the ad and a photo appear on the screen. The reader may then simply click on any of the displayed previews and read the full advertisement. It is evident that, in this case, graphics (titles, subtitles, pictures, tables, and numbers) play a significant role in creating a framing context and understanding the colony as a cohesive and coherent whole. 
4) The author of the colony is either anonymous or unnamed or the text has more authors, each of them responsible for a particular section but not for the text as a whole;

Personal advertisements in both media have anonymous authors who use different strategies to identify themselves. In The Times, the strategy is based on categorization, i.e. functionalization (in terms of what social actors do) and identification (in terms of what social actors are; further divided into classification, relational identification, and physical identification) (van Leeuwen 1996). Most advertisers identify themselves as man, male, gentleman, woman, female or lady, widow, single mum or guy from London, i.e. in terms of the classification categories "by means of which a given society or institution differentiates between classes of people" (ibid.: 54), such as age, gender, provenance, class, wealth, race, ethnicity, religion or sexual orientation. Some advertisers refer to themselves in terms of physical identification, e.g. green eyed brunette or a blonde, while others in terms of functionalization, i.e. entrepreneur, property developer etc.

Example 2:

[PAD 12] Elderly gentleman, slim, tall, elegant, seeks younger, attractive, sociable companion to share larger cabin on cruises, plus London social/cultural events (...)

[PAD 16] Tall, romantic, bear-like divorcee, 46, searching for smiling, gorgeous, tactile girl, 35-45, for Autumn walks, cuddles and great times. Ldn.

[PAD 39] Affable, soppy, cuddly teacher, young 57, likes rock, film, travel, Arts and culture, seeks intelligent, caring, childless woman, 30-60. Aim: marriage. Ldn.

The Times, November 252011

As apparent from the examples above, the advertisers use the detached form of identification (Vlčková 2000), i.e. identifying themselves and the potential partner as a female/male, lady/gentleman etc., with the verb in the third person, which has been the traditional way of self-identification from the very beginning of the existence of personal advertisements (Cocks 2009).

In the case of datingdirect.com, the advertisers use various nicknames to identify themselves. Very generally, nicknames may be either self-referential or non-self-referential. Self-referential nicknames are further divided into two categories, i.e. self-related and apparent real names, which can be first name, last name, both, or initials (Herring, Stein \& Virtanen 2013). Non-referential nicknames are connected with, for example, "a fantasy description (topdude, 
sexstar), (...) a mythical character or role (rockman, elfslayer)" (Crystal 2004: 50), a personality feature, a location, an interest, or the occupation of the advertiser. Some nicknames, on the other hand, are created by a seemingly random combination of letters and/or numbers whose meaning is probably known only to the advertiser (cf. Example 3).

Example 3:

[PAD 53] Sara - 38 - Brighton - South East Engl. 38, divorced, 5'6", green eyes $(\ldots)$

datingdirect.com, April 262010

[PAD 66] boyfromoz - 39 - Chester Le Stre. - North East Engl. 39, separated, sales/marketing (...)

datingdirect.com, April 122010

[PAD 80] Tf151 - 25 - Leeds - Yorkshire and t., 25, never married, teaching/ education $(\ldots)$

datingdirect.com, March 72011

As for self-identification and identification of the partner, in the introduction the advertisers also use the detached form, but if they include a mainstream text in their profile, they use the first person when identifying themselves, and the second person when addressing their potential partner (cf. Example 6 in Section 4).

5) A component of a colony may be used without referring to other components;

Similarly to encyclopaedias, dictionaries, or cookery books (Hoey 2001), personal advertisements in both The Times and on datingdirect.com do not need to be used with reference to other personal advertisements or other components of the newspaper/website.

6) Components may reappear in new configurations;

Generally, this feature represents rather a structural possibility and is not typical of personal advertisements as text colonies. In The Times, individual advertisements may reappear in new configurations; they may be republished in other issues. On datingdirect.com, it depends exclusively on the advertiser herself/himself whether s/he places her/his ad or rather personal profile on one or more websites and whether s/he uses the same information or changes some items.

7) Components may be added, removed or altered;

In this respect, there is an important difference between the media. In The Times, completely new components (individual advertisements) appear in each issue. On the website datingdirect.com, the components permanently change, i.e. some advertisements are added while others are removed when they have accomplished their goal, or due to other reasons. 
8) Many of the colony components perform the same function; Both advertisements published in The Times and those placed on datingdirect. com perform the same function, i.e. to identify the advertiser's personality and requirements and to elicit a response from a potential partner.

9) Jumbling components may affect the utility of the colony but the meaning remains unchanged;

This applies to advertisements from both The Times and datingdirect.com. Components (individual advertisements) may be jumbled but the meaning of the whole remains coherent although the utility may be affected if, for example, in The Times ads by men and women were mixed up. As for the online ads, these are jumbled continuously according to the selected criteria.

10) Based on previous research, Dontcheva-Navratilova adds the tenth feature: the use of controlled language, i.e. "language use characterised by considerable restrictions on text organization, and grammatical and lexical choice" (2006: 45).

Personal advertisements in both media are characterized by their language, which uses a limited set of lexico-grammatical patterns. In The Times, the restrictive factor is space. The advertisers use the same syntactic structure with a limited variation in lexis. One of the variations is presented in Example 4, where PAD 44 contains a main verb while in PAD 24 the verb phrase is absorbed in the acronym WLTM:

Example 4:

[PAD 24] Mature, retired, professional, WLTM someone warm and caring for lunch dates. Call (...)

The Times, September 10, 2011

[PAD 44] Gentle woman, 43, 5'6, blonde-haired, blue-eyed, seeks gentleman to share life with. Suffolk. Call (...)

The Times, September 10, 2011

With respect to datingdirect.com, the space restrictions are substantially lower; an advertisement in the form of mainstream text may contain from 50 to 2,000 characters, such texts naturally including a wider range of lexico-grammatical patterns (for more details about mainstream text, including examples, $\mathrm{cf}$. the following section).

\section{Analysis of simple and complex colonies}

Colonies and mainstream texts need not be strictly separated; they may be embedded in each other. As Hoey remarks, "a colony may be embedded inside 
another colony and in so doing a hierarchical organisation is normally created [...] a mainstream text can also be embedded within a colony [...] a colony may be embedded within a mainstream text" (Hoey 2001: 76). The hierarchical structure mentioned by Hoey is the criterion according to which DontchevaNavratilova (2006) classifies text colonies into simple (colony components only) and complex (colony and/or mainstream components) (Dontcheva-Navratilova 2006: 47).

Personal advertisements can be defined as sub-colonies of classified advertisements, which are themselves sub-colonies of newspapers since, as Hoey states, "a newspaper is a colony whose component parts are themselves colonies, e.g. the sports page contains football results" (Hoey 2001). Obviously, newspapers are examples of the above-mentioned embedded colonies. Nevertheless, as the following analysis shows, personal ads published in various media differ in the presence or absence of mainstream components.

Personal advertisements published in The Times are examples of simple colonies since they contain only colony components, while personal advertisements placed on the Internet website datingdirect.com belong either to simple or complex colonies since they often, but not always, contain both colony and mainstream components. There are several differences between both types where the basic difference is obvious - the advertisements differ in their length and thus in the amount of information provided. Compare the following examples:

Example 5:

[PAD 3] Gentle woman, 43, 5'6, blonde-haired, blue-eyed, seeks gentleman to share life with. Suffolk. Call... whole advertisement, The Times, September 10, 2011

[PAD 90] Ed23_2 - 42 - Newbury - South East Engl. 42, never married, consultant, 5' 4", hazel eyes, I live in Newbury, South East England (United Kingdom), I'm looking for a man between 32 and 45. introduction from datingdirect.com, April 26, 2010

As stated above, PAD 90 represents a mere introduction, followed by detailed information concerning appearance, personality, interests, and the potential partner provided in the form of a "questionnaire". Mainstream texts are often embedded in this questionnaire and their lengths can differ significantly between individual advertisements, ranging from one to eight paragraphs (one paragraph contains an average of 6 lines). Some of the advertisers use this continuous text to develop the introductory part, describing themselves and their dream partner (in this case, 29 advertisers) in more detail; some focus on describing 
their potential partner (13); and some write about their ambitions and desires, or recount interesting stories from their lives (8). The role of the mainstream text and its information value thus differ across individual advertisements. In fact, we can distinguish three variants of combinations of colony components with mainstream text.

First, colony components and mainstream text are in balance, i.e. each provides different pieces of information and thus they simply complement each other. Second, the mainstream text represents the core information containing details of the advertiser and his/her requirements with respect to the potential partner and/or the preferred type of relationship. Colony components providing only additional information then complete the frame. An example of this second variant is the whole mainstream text taken from PAD 99, which, together with the attached photo revealing the advertiser's appearance, provides an overall idea of the advertiser and the specific type of preferred relationship.

Example 6:

[PAD 99] $\mathrm{Hi}, \mathrm{I}$ am 50 years old, my interests include reading books, going to the cinema and theatre. I also enjoy watching sport (football and cricket), photography. I try to keep as fit as possible by going to the gym where I am also learning to swim. I am a non-smoking atheist, with a good sense of humour. I enjoy making new friends and would prefer to get to know someone as a friend before maybe stepping the relationship up.

datingdirect.com, March 7, 2011

The third variant is present when the role of the mainstream text is not referential but interpersonal, aiming at emotional and phatic meanings. (cf. Example 7).

Example 7:

[PAD 51] I would describe myself as fun and outgoing with a good sense of humour, though if I didn't describe myself like that, it would probably be a cause for concern!!! I can also be described as S-exy I-ntelligent $\mathrm{N}$-ice G-enerous L-oving E-xciting.

datingdirect.com, April 26, 2010

The mainstream text here has a psychological rather than an informative character, i.e. it draws on word play, humour, and emotions and thus is supposed to appeal to a certain type of reader. Obviously, the mainstream component in this example could easily be left out since all important information is contained in the questionnaire (in this case, the advertiser filled in 70 out of 81 boxes in the questionnaire; detailed description of the boxes is provided below). 
These three different variants are used approximately equally by 26 out of the 50 internet advertisers; however, the rest, i.e. 24 advertisers, did not upload a mainstream text at all and thus the information structure of their ads must benefit merely from the colony components. This is connected with another difference between printed and online advertisements, one which is related to their structural organization.

As has already been indicated, advertisers in The Times are significantly limited by space since someone wishing to place an ad needs to contact the paper by phone in order to dictate a text of no more than 25 words and to record a short voice greeting telling people more about him/herself. On the other hand, there is no form to fill in, and no instruction on how to write the ad, what should be included in it, or what words to choose. Thus, The Times advertisers are not limited with respect to content and their ads are varied and manifest a wide range of vocabulary. By contrast, advertisers on datingdirect.com choose their answers to the questionnaire according to a given template. Altogether, there are four sections with the titles About me, My profile, My lifestyle and About my date, including several further boxes which the advertiser can but does not need to fill in. The section About me includes 13 boxes labelled Occupation, Body type, Hair, Eyes etc., i.e. basic information about the advertiser. The section $M y$ profile contains 16 boxes labelled Date of birth, Town, Nationality, Appearance, Education, Astrological sign and others, i.e. more detailed information about the advertiser. The third section My lifestyle includes 14 boxes labelled My favourite films, My pets, Do I want children?, My political views etc., i.e. it focuses more on the personality and interests of the advertiser and his/her attitudes and opinions. The last section About my date contains 38 boxes called e.g. His height, His body type, His views on marriage, His eyes, His religion, Early bird or night owl?, His occupation, His exercise habits etc., i.e. information relating to various aspects of the ideal partner's personality and lifestyle. If the advertiser decides to fill in a particular box, s/he has to choose from the offered options. For example, when filling in the box called Body type, the offered options are about average, athletic, slim, a few extra pounds, curvy, heavyset or I would rather not say. Another box called My personality includes a range of 15 adjectives covering various personality features, e.g. adventurous, generous, helpful, reserved or sociable; nevertheless, advertisers can select only one option, which, to a certain extent, restricts their ability to describe themselves as thoroughly as possible and to develop their creativity, which is usually necessary in order to gain the attention of the reader. Some other boxes, e.g. Entertainment or My interests, enable the selection of more than one option, but the advertisers must still rely on the ones that are offered. This may be the reason why many advertisers use 
the mainstream text to describe themselves in their own words and to explain and/or specify features that are not included in the questionnaire. On the other hand, advertisers who choose not to add a mainstream text do not need to think much about what words to use. By the same token, advertisements in the form of a questionnaire place minimal demands on readers, since, without mainstream text, ads appear very similar, using repeated lexical expressions.

A significant difference between printed and online advertisements lies also in the graphical presentation. Most advertisers from datingdirect.com attach a photo to their ads, which is one of the strategies used to attract the attention of the readers. In this case, it is one of the sources of information and completes the frame created by colony and mainstream components. The overwhelming majority of advertisers who attach their photo do not describe their appearance and focus more on their personality, interests and idea of their potential partner. The Times, by contrast, provides space merely for text, without the possibility to attach a photo. Moreover, there are no titles, subtitles or other graphical devices completing the advertising text, except for the use of bold type for the first line of each advertisement. The only titles that can be found on the whole page are those introducing the individual sections (Men seeking women, Women seeking men, Men seeking men, Women seeking women).

\section{Conclusion}

This study dealt with personal advertisements as text colonies with the aim of comparing printed and online advertisements in terms of the presence of text-colony features. Specifically, the focus was on differences in the structural organization of printed and online personal advertisements in relation to the presence or absence of mainstream text and its function and position within the text.

As has been stated in previous studies (e.g. Dontcheva-Navratilova 2006), not all kinds of text colonies must necessarily include all ten features of such colonies. We can distinguish between central colonies, displaying all or most of the basic features, such as telephone books, dictionaries, or encyclopaedias, and peripheral colonies, displaying about half of the features, such as shopping lists or letters pages (Hoey 2001, Dontcheva-Navratilova 2006, and Tomášková 2008). This study confirms that both printed and online personal advertisements utilize the majority of the features suggested by Hoey (2001) and, thus, that they represent a central type of text colony, which is in conformity with Tárnyiková's (2002: 270) findings demonstrating that personal advertisements "represent socially structured, mostly routine-based (standardised) text colonies." 
The difference between printed and online advertisements in terms of the presence of text-colony features is in their personalization strategies, in which advertisers in The Times identify themselves in terms of the classification categories while the authors of personal profiles on datingdirect.com identify themselves by nicknames. Another difference lies in text organization: advertisers in The Times are limited by space while such restrictions are substantially lower on the datingdirect.com website.

Like all other studies, this one also faced certain limitations. The advertisements were chosen randomly from a single newspaper and a single website and, thus, the results might differ if advertisements were analysed from more sources. Also, the website datingdirect.com, as part of the dynamic Internet world, often changes the layout of personal profiles and modifies its requirements with respect to its advertisers, which influences the relevance of the results. Nevertheless, the present study may perhaps serve as a useful reference and a springboard for further research into the development of online personal advertisements.

\section{References}

Cocks, H. (2009) Classified: The Secret History of the Personal Column. London: Random House Books.

Crystal, D. (2004) Language and the Internet. Cambridge: Cambridge University Press.

Dontcheva-Navrátilová, O. (2006) 'Text colonies revisited: Clause relations in colony texts.' In: Dontcheva-Navrátilová, O. and Povolná, R. (eds) Discourse and Interaction 2. Sborník prací Pedagogické fakulty Masarykovy univerzity. Sv. 198. Brno: Masaryk University. 43-56.

Herring, S. C., Stein, D. and Virtanen, T. (2013) Pragmatics of Computer-Mediated Communication. Berlin: De Gruyter Mouton.

Hoey, M. (1996) 'A clause-relational analysis of selected dictionary entries: Contrast and compatibility in the definitions of 'man' and 'woman'.' In: Caldas-Coulthard, C. R. and Coulthard, M. (eds) Text and Practices. Reading in Critical Discourse Analysis. London and New York: Routledge. 150-165.

Hoey, M. (2001) Textual Interaction: An Introduction to Written Discourse Analysis. London: Routledge.

Tárnyiková, J. (2002) 'From mainstream text to text colonies: the case of personal advertisements.' In: Todenhagen, C. (ed.) Text, Text Structure and Text Type. Festschrift for Wolfgang Thiele. Tübingen: Stauffenburg Verlag. 269-277.

Tomášková, R. (2008) 'Textové kolonie jako organizační princip a komunikační strategie v časopisech pro ženy a pro muže.' In: Wilamová, S. and Hopkinson, C. (eds) Autorský zámér a jeho cesta $k$ adresátovi. Ostrava. 68-76.

van Leeuwen, T. (1996) 'The representation of social actors.' In: Caldas-Coulthard, C. R. and Coulthard, M. (eds) Text and Practices: Reading in Critical Discourse Analysis. London and New York: Routledge. 32-70.

Vlčková, J. (1996) ‘Text typology in personal advertising.' In: Brno Studies in English 22. Brno: Masaryk University. 89-96.

Vlčková, J. (2000) The Language of Personal Advertising in Australian Newspapers. Unpublished PhD thesis. Brno: Masaryk University. 


\section{Source:}

www.datingdirect.com

Věra Šustáčková is a doctoral student at Masaryk University, Brno, Czech Republic. Her research interests lie in the area of discourse analysis and sociolinguistics, concentrating mainly on advertising discourse.

Address: Mgr. Věra Šustáčková, Department of English and American Studies, Faculty of Arts, Masaryk University, Arne Nováka 1/1, Brno 602 00, Czech Republic. [e-mail: 105093@mail.muni.cz] 